\title{
Perancangan Sistem Fire Alarm Kebakaran Pada Gedung Laboratorium XXX
}

\author{
Muhammad Ruslan'1, M. Saleh Al Amin ${ }^{2}$, Emidiana $^{3}$ \\ Teknik Elektro, Universitas PGRI Palembang, Palembang, Indonesia ${ }^{123}$ \\ Email: ${ }^{1}$ ruslanmuhammad00@gmail.com, ${ }^{2}$ salehamin@univpgri-palembang.ac.id, \\ 3emidiana@univpgri-palembang.ac.id
}

\begin{abstract}
Fire is a phenomenon that occurs when a material reaches a critical temperature and reacts chemically with oxygen (for example) producing heat, flame, light, smoke, water vapor, carbon monoxide, carbon dioxide, or other products and effects. Fires can occur anywhere, be it in office buildings, residences or public facilities. As for other than in public areas, fires often occur, both in rooms and laboratories, the triggers are almost the same due to negligence and not being careful in using flammable tools. For this reason, the need for a fire detector with a detector system using an alarm so that once a fire occurs, all those in the building can find out through the detector with an alarm sound as a fire marker. In order to reduce casualties, the need for a sprinkler system to extinguish the fire, and can assist the officers or authorities in the building as soon as possible. From the above problems, this research will determine how many detectors and sprinklers are needed, as well as how much water volume, pump power, and ground water tank are needed. This type of research is quantitative research by direct observation of the object under study, then researchers measure the room one by one using a building meter. From the calculation results by taking a sample on the 1 st floor, the number of detectors needed is 10 smoke detectors and 3 heat detectors, the number of sprinklers is 47 , the volume of water needed is $846 \mathrm{~m}^{3}$, the pump power and ground water tank needed are hydraulic power. pump (HHP) 3,28621 kW, pump shaft power (BHP) $4.38 \mathrm{~kW}$, pump electric power (P) $6 \mathrm{~kW}$, diesel pump (PpD) 4 HP, jocky pump (PJk) $0.6 \mathrm{~kW}$, capacity GWT ( QGWT) $44 \mathrm{~m}^{3}$.
\end{abstract}

Keywords: detector system, sprinkler system, water volume, pump.

\section{LATAR BELAKANG}

Kebakaran adalah fenomena yang terjadi ketika suatu bahan mencapai suhu kritis dan bereaksi secara kimia dengan oksigen (misalnya) yang menghasilkan nyala api, panas, cahaya, uap air, asap, karbon dioksida, karbon monoksida, atau produk dan efek. Kebakaran bisa terjadi dimana saja maupun itu di gedung kantor, tempat tinggal atau fasilitas publik. Adapun selain di area umum, kebakaran sering terjadi, baik itu ruangan maupun laboratorium, pemicunya pun hampir sama karena kelalaian dan tidak berhati-hati dalam menggunakan alat yang mudah terbakar.

Jika terjadinya keterlambatan dalam penanganan akan mengakibatkan kerugian, kerugian ini bisa beraneka ragam baik kerugian jiwa atau materi. Keamanan manusia merupakan faktor utama yang menjadi pertimbangan ketika 
(Civil Engineeering, Elektrical Engineeering and Industrial Engineeering)

Vol. 18, No : 2, Oktober 2021, p-ISSN:1907-5243, e-ISSN: 2655-8416

kebakaran terjadi di sebuah bangunan. Penghuni bangunan harus mendapatkan informasi/peringatan dini ketika kebakaran segera terjadi untuk dievakuasi.

Untuk itu, Perlunya alat pendeteksi kebakaran dengan sistem detektor menggunakan alarm agar sesaat kebakaran terjadi, Semua yang berada di dalam gedung dapat mengetahui lewat pendeteksi tersebut dengan bunyi alarm sebagai penanda kebakaran. Agar dapat mengurangi korban perlunya sistem sprinkler untuk memadamkan api, serta dapat membantu petugas atau yang berwenang di gedung tersebut secepatnya.

Berdasarkan latar belakang masalah diatas, penulis memilih judul "Perancangan Sistem Fire Alarm Kebakaran Pada Gedung Laboratorium XXX“

\section{METODOLOGI PENELITIAN}

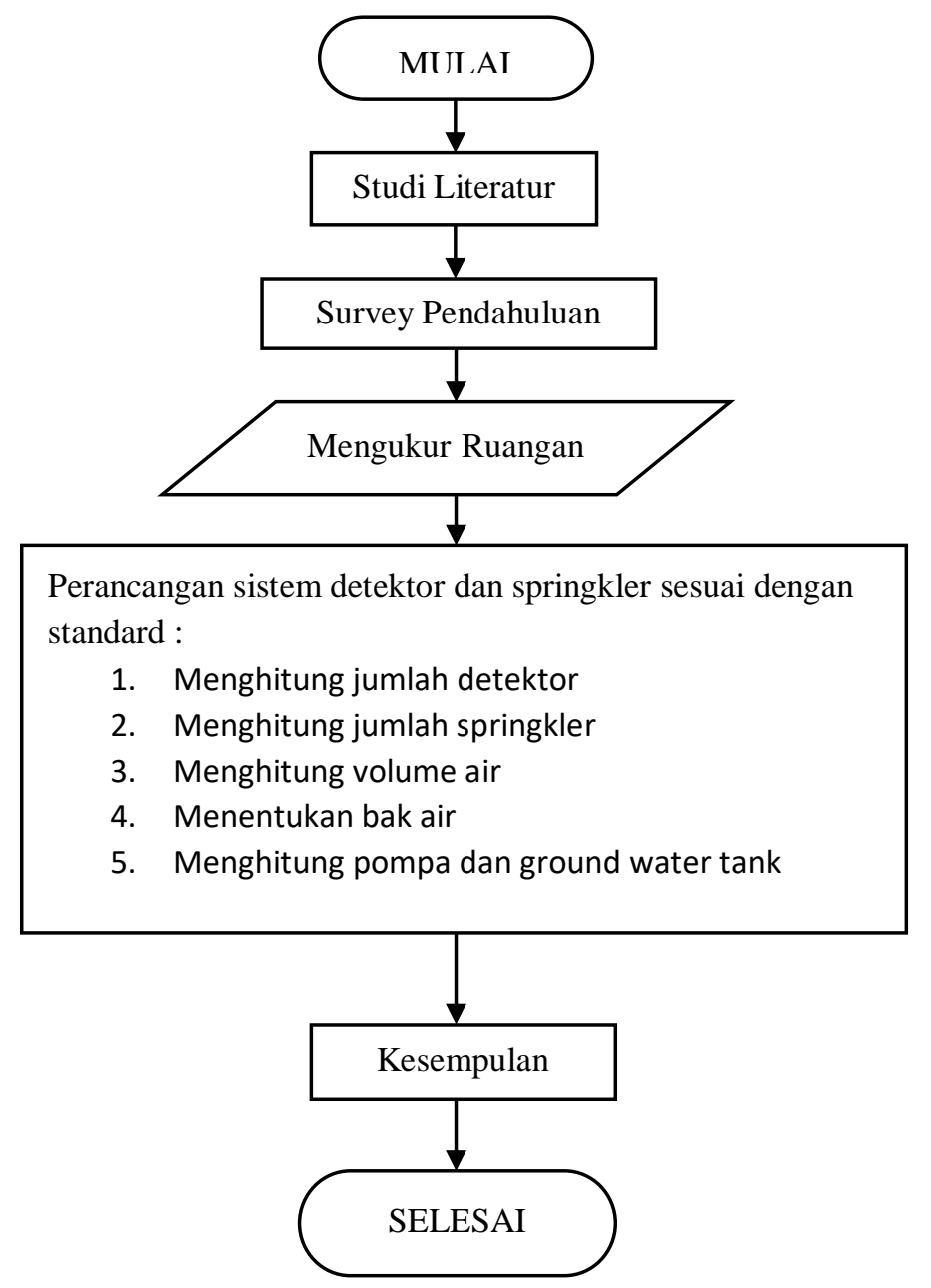

GAMBAR 1. Alur Penelitian 


\subsection{Sistem Detektor}

Detektor adalah alat untuk mendeteksi awal terjadinya kebakaran yang dapat menghidupkan alarm pada sistem.[1], sedangkan, detektor kebakaran merupakan alat yang dibuat untuk melacak kebakaran, lalu mulai melakukan suatu tindakan.[2].

\section{Jenis-Jenis Detektor}

\section{a. Smoke Detector (Detektor Asap)}

Smoke detector (detektor asap) adalah detektor yang berfungsi sesuai dengan sejumlah akumulasi asap. Fungsi detektor ini adalah untuk mendeteksi partikel asap, baik itu yang tidak terlihat maupun yang terlihat. Detektor ini dapat mendeteksi kebakaran jauh lebih cepat dari pada detektor panas. Detektor asap digunakan dengan cara yang sangat tepat di gedung-gedung di mana ada banyak kebakaran kelas A yang bisa menghasilkan asap, tetapi tidak terlalu tepat pada kebakaran gas / hidrokarbon. [3].

b. Heat Detector (Detektor Panas)

Menurut SNI 03-3985-2000 Heat Detector (Detektor Panas) adalah detektor yang bekerja berdasarkan suhu (temperature) tertentu. Detektor ini adalah detektor yang dilengkapi dengan sirkut (pneumatic) secara otomatis akan mendeteksi kebakaran melalui panas yang diterima. Sedangkan, heat detector adalah detektor tertua. Prinsip dasar, jika suhu diruangan detektor meningkat lebih tinggi dari nilai ambang batas, akan mengaktifkan alarm bekerja. Detektor panas ini lebih efektif jika dipasang dalam ruang yang rentang menyebabkan panas, (contohnya) ruang generator, ruang boiler, dapur atau seperti yang ditunjukan pada spesifikasi detector [4].

\section{c. Flame Detector (Detektor Nyala Api)}

Flame Detector (Detektor Nyala Api) ini adalah detektor yang bekerja tergantung pada radiasi kebakaran, yang setelah menerima sinyal dalam sinar inframerah atau ultra violet yang berasal dari api atau percikan api [3].

\section{d. Gas Detector (Detektor Gas)}

Ini adalah detektor yang berfungsi tergantung pada peningkatan konsentrasi gas yang timbul dari kebakaran atau gas pembakaran lainnya [5]. Secara umum, alat ini banyak digunakan di bidang atau industri yang terkait dengan tempattempat yang rentan terhadap kebocoran gas, seperti pabrik, lokasi pertambangan, kilang minyak. Fungsi dari gas detektor adalah dapat mendeteksi gas yang berbahaya untuk manusia seperti karbon dioksida serta gas lain yang mudah terbakar, dan dapat mendeteksi setidaknya 3 hal, yaitu, gas yang mudah terbakar, gas beracun, penipisan oksigen [3].

\subsection{Sistem Alarm}

Menurut SNI 03-3985-2000 Alarm kebakaran adalah komponen dari suatu sistem yang memberikan sinyal atau tanda setelah mendeteksi api. Sistem kebakaran alarm digunakan untuk memberi tahu pekerja atau penghuni di mana suhu bahan kebakaran dimulai. 
Menurut Permenaker No. 02/MEN/1983, Instalasi otomatis alarm kebakaran adalah system (serangkaian) alarm kebakaran yang menggunakan heat detector, smoke detector, detektor kebakaran nyala api dan titik panggilan secara manual dan peralatan lain diinstal dalam sistem alarm kebakaran. Sistem alarm kebakaran dilengkapi dengan sinyal atau alarm yang dapat dilihat atau didengarkan. Penempatan alarm kebakaran ini biasanya di koridor atau lorong-lorong dan jalan dalam bangunan atau instalasi.

\section{Jenis-Jenis Alarm Kebakaran}

Menurut SNI 03-3985-2000, sistem alarm kebakaran memiliki 2 jenis sistem yaitu:

\section{a. Sistem Alarm Kebakaran Manual}

Yaitu, memungkinkan seseorang untuk mendeklarasikan tanda-tanda bahaya saat memijat atau menekan tombol dengan tangan.

\section{b. Sistem Otomatis}

Yaitu, temukan api dan beri tanda itu sendiri tanpa dikendalikan oleh orangorang. Menurut Permenaker No. 02/MEN/1983 Alarm kebakaran dibagi menjadi dua jenis sesuai dengan cara kerjanya, alarm kebakaran yang memberikan sinyal atau sinyal dalam bentuk suara khusus (Audible alarm) dan alarm kebakaran yang memberikan tanda atau isyarat yang ditangkap oleh tampilan visual dengan jelas (Visible alarm).

\subsection{Sistem Sprinkler}

Sistem sprinkler merupakan sistem yang beroperasi secara otomatis menghilangkan air bertekanan ke segala arah untuk memadamkan api (setidaknya), menghindari kebakaran yang tersebar luas. Pemasangan sprinkler ini secara permanen di sebuah bangunan yang bisa memadamkan api secara otomatis saat menyemprotkan air pada awal api [6].

Pemasangan sprinkler adalah pemadam api tetap atau permanen di dalam bangunan yang dapat memadamkan api secara otomatis saat menyemprotkan air di awal api [7].

\subsection{Sistem Pompa}

Pompa adalah salah satu alat transportasi yang berfungsi untuk memindahkan cairan melalui saluran tertutup dengan mengubah energi mekanis unit ke fluida sehingga gerakan atau mengalirkan cairan dari tempat lain, secara langsung. Pompa digunakan untuk memindahkan cairan, seperti cairan, gas atau lumpur [8].

Dari penelitian yang dilakukan di Gedung Laboratorium XXX :

\section{Mengukur Denah Ruangan}

Pengukuran dilakukan dengan menggunakan meteran, pengukuran secara bertahap dengan cara mengukur satu persatu ruangan. 


\section{Menentukan Jumlah Detektor}

Langkah awal dalam menghitung jumlah kebutuhan detektor adalah dengan menentukan panjang, lebar dan tinggi setiap ruangan yang akan dipasang detektor. Selanjutnya adalah menentukan jarak antar detektor.

$\mathrm{S}=$ Jarak antar detektor

$\mathrm{S}=$ Jarak Maks x Faktor Pengali

R. efektif untuk detektor asap adalah 12

R. efektif untuk detektor panas adalah 7

$\mathbf{N}$ Memanjang $=\frac{\text { Panjang }}{\boldsymbol{S}} \mathbf{N}$ Melebar $=\frac{\text { Lebar }}{\boldsymbol{S}}$

Total jumlah kebutuhan detector

$\mathbf{N}$ Memanjang X $\mathbf{N}$ Melebar

Jarak peletakkan detektor asap $=$

Jarak detektor ke dinding $=\frac{1}{2} x S$

\section{Menentukan Jumlah Sprinkler}

Setelah mengukur denah ruangan, maka dapat ditentukan jumlah Sprinkler yang digunakan pada gedung. Jumlah Sprinkler yang digunakan pada gedung dapat dihitung menggunakan rumus :

$X=$ Jarak maksimum antara titik sprinkler $-(1 / 4 x$ jarak maksimum $)$

$L \quad=(X)^{2}$

Jumlah Sprinkler $=\frac{p x l}{\pi r^{2}}$

$\mathrm{p}=$ Panjang ruangan

$1=$ lebar ruangan

$\mathrm{r}=2,4 \mathrm{~m}$

\section{Menentukan Jumlah Volume Air}

Dalam operasi, air diperlukan untuk sprinkler yang dapat beroperasi. Volume kebutuhan air sprinkler harus dipertimbangkan sehingga tidak menyebabkan kelebihan air di sprinkler. Perhitungan volume kebutuhan air sprinkler dapat menggunakan rumus :

Rumus : $V=Q \times T$

Dimana :

$V \quad=$ Volume kebutuhan air $\left(m^{3}\right)$

$Q=$ Kapasitas air sprinkler $80 \mathrm{dm}^{3} /$ menit

$T=$ Waktu operasi sistem $=45$ menit

\section{Merancang Bak Reservoir (Bak Air)}

Dalam merangcang bak reservoir (bak air) seharusnya tidak diisi penuh, untuk itu dari hasil volume air yang ditentukan untuk menjaga faktor keamanannya, pembangunan bak air dapat ditentukan, yaitu :

Dimana :

$\mathrm{P}=$ Panjang (meter)

$\mathrm{L}=$ Lebar (meter)

$\mathrm{K}=$ Kedalaman (meter) 
(Civil Engineeering, Elektrical Engineeering and Industrial Engineeering)

Vol. 18, No : 2, Oktober 2021 , p-ISSN:1907-5243, e-ISSN: 2655-8416

Volume total bak air (Reservoir) $\left(V_{\text {bak }}\right.$ air $)$ :

$V_{\text {bak air }}=\mathrm{p} \times 1 \times \mathrm{k}$

Selisih volume

$\Delta V=$ Vbak air $-\mathrm{V}($ kebutuhan air $)$

\section{Menentukan daya Pompa}

Penentuan daya pada pompa dalam sistem ini dapat dihitung dalam perhitungan dibawah ini :

\section{Daya Hidrolik Pompa (HHP)}

HHP $=\mathrm{Q}\left(\mathrm{m}^{3} / \mathrm{dt}\right) \times\left(\mathrm{H}_{\mathrm{d}}-\mathrm{H}_{\mathrm{s}}\right) \mathrm{m} \times \mathrm{S}_{\mathrm{g}}\left(\mathrm{kg} / \mathrm{m}^{3}\right) \times \mathrm{g}\left(\mathrm{m} / \mathrm{dt}^{2}\right)$

Dimana :

HHP = daya hidrolik pompa

$\mathrm{Q}\left(\mathrm{m}^{3} / \mathrm{dt}\right) \quad=$ air yang di butuhkan $\left(\mathrm{m}^{3} / \mathrm{s}\right)$

$\left(\mathrm{H}_{\mathrm{d}}-\mathrm{H}_{\mathrm{s}}\right) \mathrm{m}=$ Heat

$\mathrm{S}_{\mathrm{g}}\left(\mathrm{kg} / \mathrm{m}^{3}\right) \quad=$ Berat jenis cairan $\left(\mathrm{kg} / \mathrm{m}^{3}\right)=998 \mathrm{~kg} / \mathrm{m}^{3}$ (untuk air)

$\mathrm{g}\left(\mathrm{m} / \mathrm{dt}^{2}\right) \quad=$ Gravitasi bumi $\left(\mathrm{m} / \mathrm{dt}^{2}\right)=9,8 \mathrm{~m} / \mathrm{dt}^{2}$

Daya Shaft Pompa (BHP).

$\mathrm{BHP}=\frac{\mathrm{HHP}}{\eta \mathrm{p}} \mathrm{kW}$

Dimana :

$\mathrm{BHP}=$ daya shaft pompa

$\eta \mathrm{p}=$ efesiensi standar pompa $=0,75$

Daya Listrik Pompa (P)

$\mathrm{P} \quad=\frac{(\mathrm{BHP}) \cdot(1+\alpha)}{\eta \mathrm{t}}$

Dimana :

$\mathrm{P} \quad=$ daya listrik pompa

$\alpha \quad=$ faktor cadangan (pecahan) $=0,2$

$\eta \mathrm{t}=$ efesiensi transmisi $($ pecahan $)=0,95$

Pompa Diesel

$\mathrm{P}_{\mathrm{pD}} \quad=\left(\frac{\mathrm{QT}}{p D}\right) \cdot(\mathrm{P}) \mathrm{kW}$

Dimana :

$\mathrm{P}_{\mathrm{pD}} \quad$ = daya pompa diesel

$\mathrm{pD}=$ efisiensi pompa diesel diasumsikan $=80 \%$

Pompa Jocky

$\mathrm{P}_{\mathrm{Jk}} \quad=(0,1) \cdot(\mathrm{P}) \mathrm{kW}$

Total Kapasitas GWT

$\mathrm{Q}_{\mathrm{GWT}}=\left(\mathrm{P}_{\mathrm{PD}}+\mathrm{Q}_{\mathrm{T}}\right) \mathrm{m}^{3}$

\section{HASIL DAN PEMBAHASAN}

\subsection{Menghitung Jumlah Detektor}

Menghitung kebutuhan detektor dilakukan untuk menghitung jumlah kebutuhan detektor asap dan detektor panas lantai 1 di Gedung Laboratorium XXX. 
Jadi jumlah kebutuhan detektor untuk ruang tempat wudhu adalah 1 buah detektor asap. Jarak antar detektor adalah 12 meter dan jarak detektor asap ke dinding adalah 6 meter.

Tabel 1. Perhitungan Jumlah Detektor

\begin{tabular}{llcccc}
\hline NO & \multicolumn{1}{c}{ Ruangan } & $\mathbf{P}$ & $\mathbf{L}$ & Detektor & Jumlah \\
\hline $\mathbf{1}$ & Operator & $5,26 \mathrm{~m}$ & $4,9 \mathrm{~m}$ & Asap & 1 \\
$\mathbf{2}$ & Lab. Hydrologi & $8,84 \mathrm{~m}$ & $6,9 \mathrm{~m}$ & Asap & 1 \\
$\mathbf{3}$ & Lab. PGSD & $8,9 \mathrm{~m}$ & $6,9 \mathrm{~m}$ & Asap & 1 \\
$\mathbf{4}$ & Lab. Ilmu Ukur Tanah & $8,87 \mathrm{~m}$ & $6,9 \mathrm{~m}$ & Panas & 1 \\
& dan Struktur & & & \\
$\mathbf{5}$ & Lab. Pengukuran Listrik & $8,84 \mathrm{~m}$ & $6,84 \mathrm{~m}$ & Panas & 1 \\
& dan Rangkaian Listrik & & & & \\
$\mathbf{6}$ & Ruang Lobby & $8,9 \mathrm{~m}$ & $6,84 \mathrm{~m}$ & Asap & 1 \\
$\mathbf{7}$ & Lab. Pendidikan Kimia & $8,87 \mathrm{~m}$ & $6,84 \mathrm{~m}$ & Panas & 1 \\
$\mathbf{8}$ & Tempat Jalan & $36,62 \mathrm{~m}$ & $10,48 \mathrm{~m}$ & Asap & 3 \\
$\mathbf{9}$ & Toilet Laki-Laki & $3,32 \mathrm{~m}$ & $3,47 \mathrm{~m}$ & Asap & 1 \\
$\mathbf{1 0}$ & Toilet Perempuan & $3,32 \mathrm{~m}$ & $2,71 \mathrm{~m}$ & Asap & 1 \\
$\mathbf{1 1}$ & Tempat Wudhu & $1,68 \mathrm{~m}$ & $1,7 \mathrm{~m}$ & Asap & 1 \\
\hline
\end{tabular}

\subsection{Menentukan Jumlah Sprinkler}

- Kebutuhan air untuk bahaya kebakaran ringan 225 liter $/$ menit $=3,75$ liter $/$ detik $=0,0038 \mathrm{dm}^{3} / \mathrm{s}(\mathrm{SNI} 03-3989-2000)$

- Lubang sprinkler $=0,5$ inchi

- Direncanakan antara satu sprinkler dengan sprinkler yang lain terjadi overlapping sebesar $1 / 4$ area jangkauan, sehingga tidak ada titik yang tidak terkena pancaran air

Maka jarak jangkauan sprinkler, yang dapat dihitung yaitu :

$\mathrm{x}=$ jarak maksimum antar titik sprinkler $-(1 / 4)$. jarak maksimum

$$
=4,6 \mathrm{~m}-(1 / 4 \times 4,6 \mathrm{~m})
$$

$$
=3,45 \mathrm{~m}
$$

Maka, $\mathrm{L}=3,45 \mathrm{~m} \times 3,45 \mathrm{~m}$

$$
=11,9 \mathrm{~m}^{2}
$$

Dari hasil pengukuran ruangan dan menghitungan data yang dilakukan pada Gedung Laboratorium XXX, maka jumlah sprinkler yang dibutuhkan adalah 47 sprinkler.

Tabel 2. Perhitungan Jumlah Sprinkler

\begin{tabular}{lcc}
\hline Ruang & Luas $\left(m^{2}\right)$ & $\begin{array}{c}\text { Jumlah } \\
\text { Sprinkler }\end{array}$ \\
& & 2 \\
Operator & 25,77 & 5 \\
Lab. Hydrologi & 60,99 & 5 \\
Lab. PGSD & 61,41 &
\end{tabular}


(Civil Engineeering, Elektrical Engineeering and Industrial Engineeering)

Vol. 18, No : 2, Oktober 2021 , p-ISSN:1907-5243, e-ISSN: 2655-8416

\begin{tabular}{lcc} 
Lab. Ilmu Ukur Tanah Dan & 61,20 & 5 \\
Struktur & 60,46 & 5 \\
Lab. Pengukuran Listrik Dan & & 5 \\
Rangkaian Listrik & 60,67 & 5 \\
Lab. Pendidikan Fisika & 60,87 & 12 \\
Ruang Lobby & 126,55 & 1 \\
Tempat Jalan & 11,52 & 1 \\
Toilet Laki-Laki & 8,99 & 1 \\
Toilet Perempuan & 2,85 & 47 \\
Tempat Wudhu & 541,28 & \\
Jumlah & & \\
\hline
\end{tabular}

\subsection{Volume Persediaan Air}

Dalam operasi, air diperlukan untuk sprinkler yang dapat beroperasi.

Volume kebutuhan air sprinkler harus dipertimbangkan sehingga tidak menyebabkan kelebihan air di sprinkler. Perhitungan volume kebutuhan air sprinkler dapat menggunakan rumus :

$\mathrm{V}=\mathrm{Q} \times \mathrm{T}$

Dimana :

$\mathrm{V}=$ Volume kebutuhan air $\left(\mathrm{m}^{3}\right)$

$\mathrm{Q}=$ Kapasitas air sprinkler $\left(\mathrm{dm}^{3} /\right.$ menit $)$

$=80 \mathrm{dm}^{3} /$ menit $x 47$ Sprinkler

$=3.760 \mathrm{dm}^{3} /$ menit

$\mathrm{T}=$ Waktu operasi sistem diasumsikan 45 menit

$\mathrm{V}_{(\text {kebutuhan air })}=\mathrm{Q} \times \mathrm{T}$

$$
\begin{aligned}
& =3760 \mathrm{dm}^{3} / \text { menit } \times 45 \text { menit } \\
& =169.200 \mathrm{dm}^{3}=169,2 \mathrm{~m}^{3}
\end{aligned}
$$

Jadi, $V_{(\text {kebutuhan air })}$ untuk sprinkler $=169,2 \mathrm{~m}^{3}$

Total Penggunaan Air Kebakaran Adalah :

Total penggunaan air kebakaran untuk 5 lantai yang diasumsikan, jadi :

$\mathrm{V}_{(\text {kebutuhan air) }}=5 \times 169,2 \mathrm{~m}^{3}$

$$
=846 \mathrm{~m}^{3}
$$

Bila pada saat terjadi kebakaran, diestimasikan hanya satu seksi dari lantai $(25 \%$ dari lantai), maka banyaknya kebutuhan air untuk pemadaman kebakaran yaitu :

$\begin{array}{ll}\mathrm{Q}_{\mathrm{T}} & =\left(\frac{846}{24}\right) \mathrm{m}^{3} \\ \mathrm{Q}_{\mathrm{T}} & =35,25 \mathrm{~m}^{3} \text { dibulatkan menjadi }=40 \mathrm{~m}^{3} .\end{array}$

\subsection{Bak Reservoir (Bak Air)}

Dalam merangcang bak reservoir (bak air) seharusnya tidak diisi penuh, untuk itu dari hasil volume air yang ditentukan untuk menjaga faktor keamanannya, pembangunan bak air dapat ditentukan, yaitu:

Panjang = 10 meter 
Lebar

Kedalaman

$$
\begin{aligned}
& =9 \text { meter } \\
& =10 \text { meter }
\end{aligned}
$$

Volume total bak Reservoir (bak air) ( $\left.V_{\text {bak air }}\right)$ :

$V_{\text {bak air }}=\mathrm{p} \times 1 \times \mathrm{k}$

$$
=10 \mathrm{~m} \times 9 \mathrm{~m} \times 10 \mathrm{~m}=900 \mathrm{~m}^{3}
$$

Selisih volume

$$
\begin{aligned}
\Delta V \quad= & \text { Vbak air }-\mathrm{V}(\text { kebutuhan air }) \\
& =900 \mathrm{~m}^{3}-846 \mathrm{~m}^{3}=54 \mathrm{~m}^{3}
\end{aligned}
$$

\subsection{Menentukan Daya Pompa}

Menentuan daya pada pompa dan ground water tank dalam sistem ini dapat dihitung dalam perhitungan di bawah ini :

\section{Pompa Elektrik yang digunakan adalah :}

Kapasitas GWT yang dibutuhkan adalah $430 \mathrm{~m}^{3}$, dikeluarkan untuk memenuhi kebutuhan sprinkler selama 45 menit satu seksi lantai.

Maka kapasitas pompa yang harus melayaninya adalah :

$$
\begin{array}{ll}
\mathrm{Q} & =\left(\frac{40}{45}\right) \mathrm{m}^{3} / \text { menit } \\
\mathrm{Q} & =0,88 \mathrm{~m}^{3} / \text { menit } \\
\mathrm{Q} & =0,014 \mathrm{~m}^{3} / \text { detik } \\
\text { Heat } & =24 \mathrm{~m}
\end{array}
$$

$\mathrm{S}_{\mathrm{g}}$ : Berat jenis cairan $\left(\mathrm{kg} / \mathrm{m}^{3}\right)=998 \mathrm{~kg} / \mathrm{m}^{3}$ (untuk air)

$\mathrm{g}$ : Gravitasi bumi $\left(\mathrm{m} / \mathrm{dt}^{2}\right) \quad=9,8 \mathrm{~m} / \mathrm{dt}^{2}$

Maka :

\section{Daya Hidrolik Pompa (HHP)}

$$
\begin{aligned}
\mathrm{HHP} & =\mathrm{Q}\left(\mathrm{m}^{3} / \mathrm{dt}\right) \times\left(\mathrm{H}_{\mathrm{d}}-\mathrm{H}_{\mathrm{s}}\right) \mathrm{m} \times \mathrm{S}_{\mathrm{g}}\left(\mathrm{kg} / \mathrm{m}^{3}\right) \times \mathrm{g}\left(\mathrm{m} / \mathrm{dt}^{2}\right) \\
& =(0,014) \cdot(24) \cdot(998) \cdot(9,8) \\
& =3.286,21 \mathrm{watt} \\
& =3,28621 \mathrm{~kW} .
\end{aligned}
$$

\section{Daya Shaft Pompa (BHP)}

$\eta_{\mathrm{p}}:$ efesiensi standar pompa $=0,75$

Maka :

$$
\begin{aligned}
\text { BHP } & =\frac{H H P}{\eta p} \mathrm{~kW} \\
\text { BHP } & =\frac{3,28621}{0,75} \mathrm{~kW} . \\
\text { BHP } & =4,38 \mathrm{~kW}
\end{aligned}
$$

\section{Daya Listrik Pompa (P)}

$\alpha \quad=$ faktor cadangan (pecahan) $=0,2$

$\eta \mathrm{t}=$ efesiensi transmisi $($ pecahan $)=0,95$ 
(Civil Engineeering, Elektrical Engineeering and Industrial Engineeering)

Vol. 18, No : 2, Oktober 2021 , p-ISSN:1907-5243, e-ISSN: 2655-8416

$\mathrm{P} \quad=\frac{(\mathrm{BHP}) \cdot(1+\alpha)}{\eta \mathrm{m}}$

Maka :

$\mathrm{P} \quad=\frac{(\mathrm{BHP}) \cdot(1+\alpha)}{\eta \mathrm{t}}$

$\mathrm{P} \quad=\frac{(4,38) \cdot(1,2)}{0,95}$

$\mathrm{P} \quad=5,53 \mathrm{~kW}$ dibulatkan menjadi :

$\mathrm{P} \quad=6 \mathrm{~kW}$ (Pembulatan)

\section{Pompa Diesel yang digunakan adalah :}

Efisiensi pompa diesel diasumsukan sebesar $80 \%$, maka kapasitas pompa diesel adalah :

$\mathrm{P}_{\mathrm{pD}} \quad=\left(\frac{Q T}{p D}\right) \cdot(\mathrm{P}) \mathrm{kW}$

$\mathrm{P}_{\mathrm{PD}}=\left(\frac{40}{80}\right) \cdot(6)$

$\mathrm{P}_{\mathrm{pD}}=3 \mathrm{~kW}$

$\mathrm{P}_{\mathrm{pD}}=4,02 \mathrm{HP}$ dibulatkan menjadi : $4 \mathrm{HP}$

\section{Pompa Jocky yang digunakan adalah:}

Besarnya pompa Jocky yang dibutuhkan adalah

$\mathrm{P}_{\mathrm{Jk}} \quad=(0,1) \cdot(\mathrm{P}) \mathrm{kW}$

$\mathrm{P}_{\mathrm{Jk}} \quad=(0,1) \cdot(6) \mathrm{kW}$

$\mathrm{P}_{\mathrm{Jk}} \quad=0,6 \mathrm{~kW}$

\section{Total Kapasitas GWT adalah :}

$\mathrm{Q}_{\mathrm{GWT}}=\left(\mathrm{P}_{\mathrm{pD}}+\mathrm{Q}_{\mathrm{T}}\right) \mathrm{m}^{3}$

$\mathrm{Q}_{\mathrm{GWT}}=(4+40) \mathrm{m}^{3}$

$\mathrm{Q}_{\text {GWT }}=44 \mathrm{~m}^{3}$

Dari semua hasil perhitungan data ruangan yang diukur pada Gedung Laboratorium XXX dengan mengambil sempel lantai 1 dan dikarenakan luas bangunan pada lantai 1-5 itu sama, maka diasumsikan 5 lantai itu sama, untuk itu dari semua hasil perhitungan data ruangan yang didapat yaitu pada tabel berikut :

Tabel 3. Perhitungan Semua Hasil

\begin{tabular}{lc}
\hline Jumlah detektor & 10 Detektor Asap dan 3 Detektor \\
& Panas \\
Jumlah sprinkler lantai 1 & 47 Sprinkler \\
Jumlah sprinkler 5 lantai yang & 235 Sprinkler \\
diasumsikan & \\
Volume air lantai 1 & $169,2 \mathrm{~m}^{3}$ \\
Volume air 5 lantai yang diasumsikan & $846 \mathrm{~m}^{3}$ \\
Bak air lantai 1 & $10,8 \mathrm{~m}^{3}$ \\
Bak air 5 lantai yang diasumsikan & $54 \mathrm{~m}^{3}$ \\
\hline
\end{tabular}


Daya pompa $6 \mathrm{~kW}$

GWT $44 \mathrm{~m}^{3}$

\section{KESIMPULAN}

Dari hasil perhitungan dengan mengambil sempel lantai 1, didapat jumlah kebutuhan detektor sebanyak 10 buah detektor asap dan 3 buah detektor panas, jumlah sprinkler sebanyak 47 buah, volume air yang dibutuhkan sebanyak $846 \mathrm{~m}^{3}$, daya pompa dan ground water tank yang dibutuhkan yaitu, daya hidrolik pompa (HHP) 3,28621 kW, daya shaft pompa (BHP) 4,38 kW, daya listrik pompa (P) 6 $\mathrm{kW}$, pompa diesel $\left(\mathrm{P}_{\mathrm{pD}}\right) 4 \mathrm{HP}$, pompa jocky $\left(\mathrm{P}_{\mathrm{Jk}}\right)$ 0,6 kW, kapasitas GWT ( $\left.\mathrm{Q}_{\mathrm{GWT}}\right)$ $44 \mathrm{~m}^{3}$.

\section{DAFTAR PUSTAKA}

[1] Depnakertrans (1983) 'Peraturan Menteri Tenaga Kerja Republik Indonesia Nomor: Per.02/Men/1983 Tentang Instalasi Alarm Kebakaran Automatik', pp. 1-25.

[2] Badan Standar Nasional Indonesia (2000b) 'Tata cara perencanaan sistem protekasi pasif untuk pencegahan bahaya kebakaran pada bangunan rumah dan gedung.', Sni 03 - 1736 - 2000, pp. 1-83. Available at: http://dppk.bandung.go.id/assets/uploads/file/4fee4-sni-springkler.pdf.

[3] Ningrum, N. N. (2019) 'Kebakaran Di Gedung Universitas X Tahun 2019', Fakultas Kesehatan Masyarakat.

[4] Tologo, L. A. P. (2011) 'Studi Instalasi Fire Alarm Kampus Teknik Gowa', Universitas Hasanuddin.

[5] Setyawan, A. C. (2010) 'Tugas akhir perancangan sistem detektor, alarm dan sistem sprinkler pada gedung plaza dan gedung direktorat ppns-its', Perancangan Sistem Detektor, Alarm, Sistem Sprinklerpada Gedung Plaza dan Gedung Direktorat PPNS-ITS.

[6] Amalia, R. S. (2012) 'PERANCANGAN DAN PEMASANGAN SISTEM SPRINKLER Fakultas Teknik Sipil dan Perencanaan Universitas Gunadarma', (16309863).

[7] Badan Standar Nasional Indonesia (2000a) 'SNI 03-3989-2000 Tata cara perencanaan dan pemasangan sistem springkler otomatik untuk pencegahan bahaya kebakaran pada bangunan gedung .', Badan Standart Nasional, pp. 183.

[8] Lingkup, R. and Lingkup, R. (2001) 'Spesifikasi instalasi pompa yang dipasang tetap untuk proteksi kebakaran', p. 6570. 